Review article

\title{
Musculoskeletal etymology: What's in a name?
}

\author{
Dr Anuj Agrawal, Associate Professor \\ Dept. of Orthopaedics, Kamineni Academy of Medical Sciences and Research Centre, Hyderabad
}

\section{A R T I C L E I N F O}

\section{Article history:}

Received 2 October 2017

Received in revised form 9 February 2018

Accepted 22 February 2018

Available online 23 February 2018

\section{Keywords:}

Etymology

Medical etymology

Musculoskeletal etymology

Nomenclature of bones and muscles

Orthopaedic terminology

\section{A B S T R A C T}

Medical etymology refers to the origins and developments of medical terms, mostly derived from Greek and Latin languages. A study of etymology helps a physician develop useful insight into body parts and diseases, relating them with the history of mankind. The bones and muscles of the body have an interesting and imaginative etymology, the locomotory system playing a pivotal role in evolution of the human race and cultures. This paper reviews the musculoskeletal etymology as pertaining to orthopaedics, highlighting the resemblance of bones and muscles to day-to-day objects and their interesting applications by early man.

\section{Introduction}

'Etymology' refers to the origins and developments in the meaning of a word or a term. Over $80 \%$ of medical etymology comes from Greek and Latin, and other languages like Arabic, French, German, Hindi, Spanish etc. have meagre contributions to it. $^{1}$ A knowledge of medical etymology helps physicians and surgeons develop interesting insight into the body parts and diseases and brings us into contact with the "history of medicine, of human ideas, and of human struggle to understand the forces of nature that determine human destiny and mortality" as quoted by John Dirckx. ${ }^{2}$

In this article, we have reviewed the etymology of the bones and muscles of the upper and lower limbs and the back. Other body segments (like head and neck, thorax and abdomen) not pertaining to orthopaedics have been excluded from this review to keep it concise. The origin and derivation of many medical terms are debatable with no consensus in the history. We have presented widely cited and seemingly probable origins of the words, recognizing the fact that other views too are prevalent in many instances.

\section{Musculoskeletal etymology}

\subsection{Lower limb}

The lower limb extends from the pelvic girdle to the foot, consisting of important bones and muscles responsible for weight-

E-mail address: ortho.kk@kaminenihospitals.com (A. Agrawal). bearing and locomotion. 'Pelvis' means a large bowl or basin, reflecting the bowl-like interior of the bone. ${ }^{3}$ The pelvic bone has been referred to as the 'innominate' (without a name) bone, failing to attract a name from anatomists, though the three bones constituting it have been named as the 'ilium' (loin bone), 'ischium' (hip bone) and 'pubis' (groin bone). ${ }^{4}$ The latter bears the Latin name os pectineum (pectin means comb) due to the comb-like appearance of the pubic body and rami (Fig. 1a). ${ }^{1}$ The muscle originating from it is thus named 'pectineus'. The cup-like socket of the hip joint has been named as 'acetabulum', which means a small vessel or cup for vinegar (Fig. 1b). ${ }^{3}$ The acetabulum was used as a liquid measure by ancient Roman physicians. The non-articular central part of the acetabulum is similarly called the 'cotyloid fossa' (kotule means cup). The ligamentum teres is attached to the cotyloid fossa and helps to locate the true acetabulum during open reduction of dysplastic hips.

The 'femur' has an unknown etymology and is probably derived from some architectural term. The kneecap was named as 'patella' (dish or pan) due to the round shape of the bone. The shinbones were named as 'tibiae' (flute) as these were used to make wind instruments like flutes by early man (Fig. 2a). ${ }^{3}$ The adjacent slender, long bone was named as 'fibula' (brooch) comparing to a Roman brooch or clasp (Fig. 2b) and the muscles attached to the fibula were similarly named as 'peronei' (pins of brooch). ${ }^{1}$

The tarsal (tarsus means ankle) bones have an interesting etymology too. The tetrahedral anklebones or 'knucklebones' of animals like horse, goat, sheep etc. were used as dice (used for playing games) by the Romans (Fig. 3a), and the anklebone was thus named as 'talus' (tallux means die). ${ }^{1,4}$ The Mongolians still use the tali as dice ('shagai') for playing or fortune-telling. The earlier 
(a)

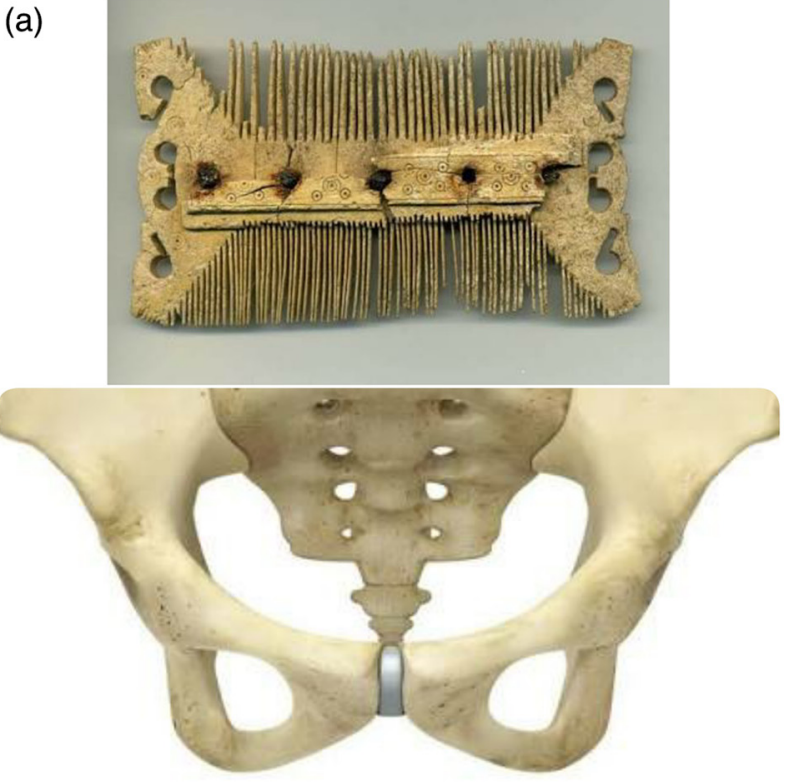

(b)

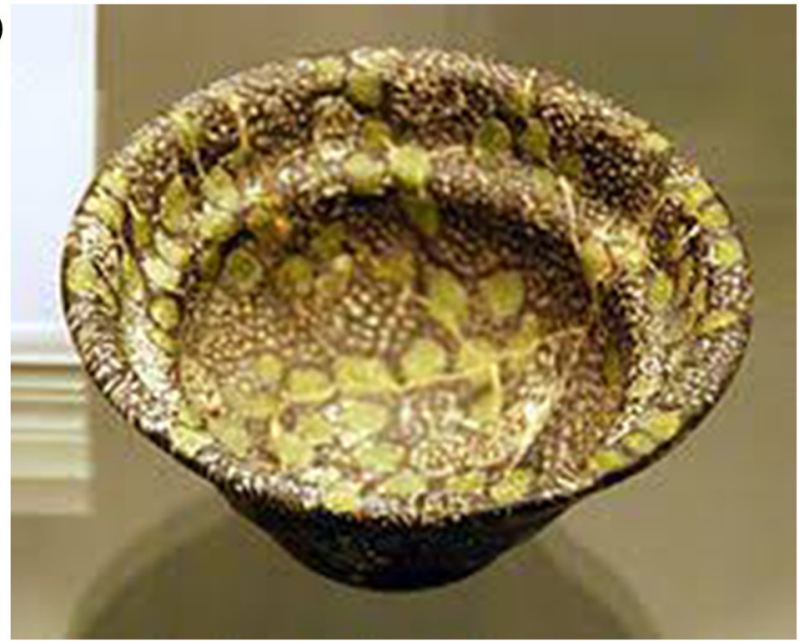

Fig. 1. Etymology of the pelvic bone (a) comb-shaped pubis (os pecten) (b) acetabulum is a small vinegar cup used by Romans.

name for talus was astragalus, which too refers to dice in Greek. ${ }^{4}$ The second cervical vertebra (or axis) was also earlier called as astragalus, as the second cervical vertebra of sheep was used as dice by Greeks, after removing the posterior arches. ${ }^{4}$ Currently, the name astragalus is not preferred for either of these bones to avoid confusion. The calcaneum or os calcis (calx means chalk or limestone) was so named because of a fancied resemblance to the stone (Fig. 3b). ${ }^{1}$ Other tarsal bones were too named on the basis of their shapes, like navicular (small ship), cuboid (cube-like) and cuneiform (wedge-shaped). It should be noted that the human navicular doesn't much resemble a ship or boat, but the name might have been derived for equine navicular which is boat-shaped (Fig. 3c).

Bones of the forefoot have similar names as those in hands. 'Metatarsals' (meta means change) reflect a transition from the toes to the tarsal region, while 'phalanx' refers to an ancient Greek military formation consisting of several rows of soldiers standing close together, similar to the arrangement of phalanges in feet and hands (Fig. 3d). ${ }^{4}$ Phalanx was a popular military tactic in earlier times. The Macedonian phalanx of Alexander with $5 \mathrm{~m}$ long spears (sarissas) remained invincible for over two centuries, establishing (a)

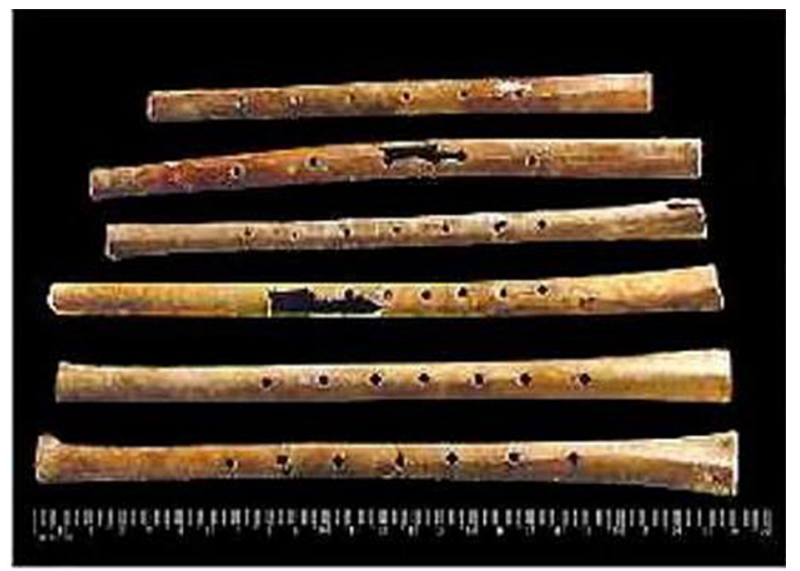

(b)

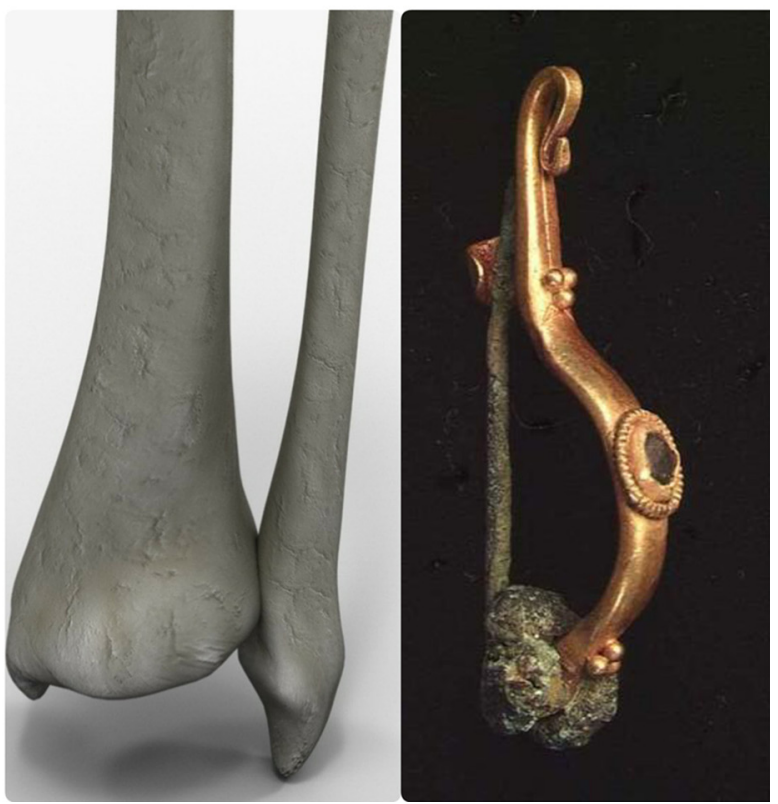

Fig. 2. Etymology of leg bones (a) animal tibiae were used as flutes by early man (b) brooch-shaped fibula.

his rule over a large part of the world. ${ }^{5}$ The original Greek phalanx used to be rectangular with heavily armed infantry, though the term was later applied for any massed infantry formation, regardless of its equipment. ${ }^{5}$ Ancient Hindu epics like the Mahabharata too mention of such infantry formations as Vyuhas. Chakravyuha was a complex circular phalanx considered nearly impregnable. The word 'phalanx' has entered common English usage to mean 'any group of people or things of similar type forming a close unit'. 6

The muscles of the lower limb are named on the basis of their appearance e.g. piriformis (pear-shaped, Fig. 4a), quadriceps (fourheaded), gracilis (slender), soleus (flat sandal); location e.g. glutei major/medius/minor, tibialis anterior/posterior, popliteus; or function e.g. adductor longus/brevis/magnus, flexor/extensor digitorum longus/brevis. The 'sartorius' (sartor means tailor) muscle has also been named on the basis of its function, as it flexes/externally rotates the hip and flexes/internally rotates the knee, as required in sitting cross-legged during sewing by a tailor. ${ }^{1}$ The tendinous attachment of the medial hamstrings (sartorius, gracilis and semitendinosus) at the proximal medial tibia resembles the appearance of a goose's foot (Fig. 4b) and has been thus named as 'pes anserinus' (pes means foot, anser means goose). ${ }^{3}$ Pes anserine bursitis is an important cause of medial knee pain, often masquerading as medial compartment gonarthrosis. 
(a)

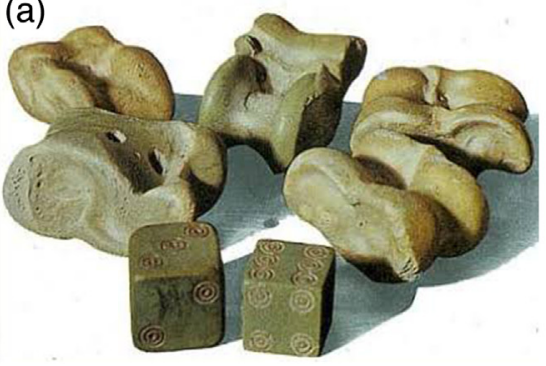

(b)

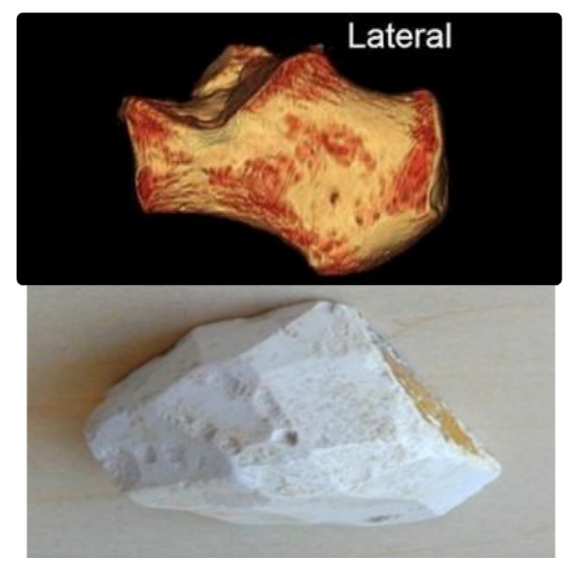

(c)

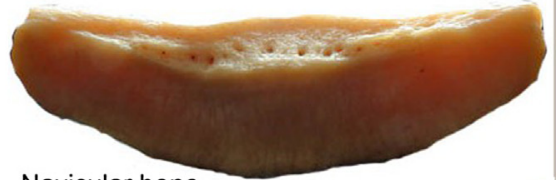

Navicular bone

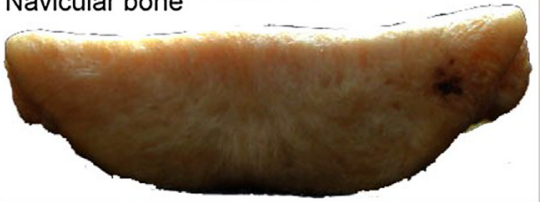

(d)

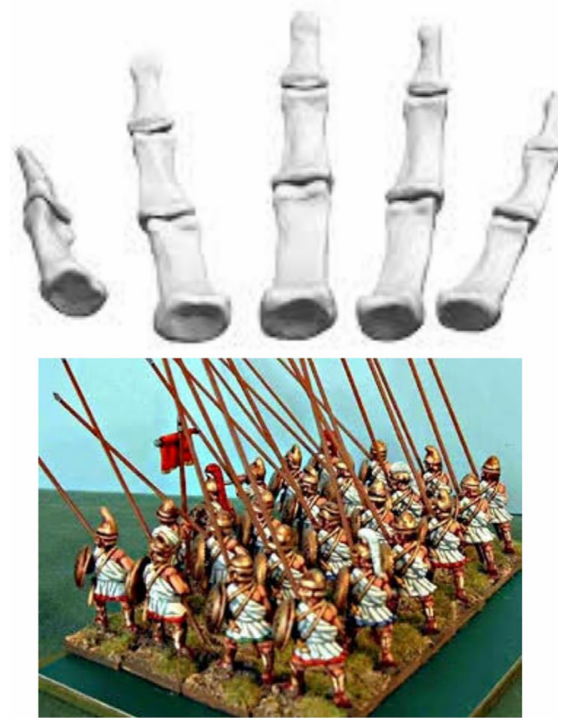

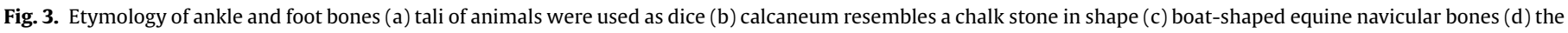
arrangement of phalanges resembles that of soldiers in a military phalanx.

Some consider it a tendo-bursitis rather than just bursitis, calling it 'anserine syndrome'.

The tendon of the triceps surae muscles (medial/lateral gastrocnemii and soleus), which is the largest tendon in the body ('chorda magna'), has been named as the 'Achilles' tendon, based on popular Greek mythology. Achilles was a great warrior hero of the Iliad who was killed by a poisoned arrow shot at his heel chord during the Trojan war (Fig. 4c). His whole body was made immortal in infancy by dipping in the river Styx, but only his heel chords remained vulnerable as he was held by them by his mother during the dip (Fig. 4d). ${ }^{1}$ The word 'Achilles heel' has entered common English usage, meaning 'a weakness or vulnerable point'. ${ }^{6}$ True to its name, Achilles tendon is one of the most vulnerable tendons in the body to develop tendinopathy and tears, often requiring surgical treatment.

\subsection{The upper limb}

The upper limb extends from the pectoral girdle to the fingers, consisting of important bones and muscles responsible for the human dexterity and prehensile action. The pectoral girdle (pectus = chest) in humans consists of two bones- clavicle and scapula, though most animals have three bones, with coracoid as a separate bone. 'Clavicle' (small key) derives its name from a fanciful comparison to ancient Roman latch keys (Fig. 5a), though some believe the name to be derived from tortuous tendrils of plants. ${ }^{1,3}$ 'Scapula' means spades or shovels, and shoulder blades of large animals like oxen were used as shovels in the Neolithic age (Fig. 5b). ${ }^{4}$ The hook-like anterior process of the scapula is called the 'coracoid' (raven or crow), resembling the crooked beak of a raven
(Fig. 5c). ${ }^{3}$ The lateral process of the scapula is called the 'acromion' (akros means highest or extreme point) (Fig. 5c).

The long bones of the upper limb have been unimaginatively named, with 'humerus' referring to shoulder (omos means shoulder, as in omohyoid) and 'ulna' referring to elbow (olena means elbow, as in olecranon).3,4 'Radius' (spoke of wheel, ray or staff) has been so named probably because of its staff-like shape. ${ }^{1}$ The carpal (carpus means wrist) bones are named more imaginatively based on their shapes- 'scaphoid' (boat-shaped, Fig. 6a), 'lunate' (moon-shaped, Fig. 6b), 'triquetrum' (threecornered or pyramidal, Fig. 6c), 'pisiform' (pea-like), 'trapezium'/ 'trapezoid' (trapezium-shaped), 'capitate' (headed, Fig. 6d), 'hamate' (hooked, Fig. 6e). The carpal bones were known by different names historically and it is important to know these in order to correctly search and interpret older literature (Fig. 7). It should be noted that two of the carpal bones were earlier known by the names of tarsal bones- scaphoid as 'carpal navicular' and triquetrum as 'carpal cuneiform', causing much confusion.

Scaphoid is sometimes referred to as the bone of the snuffbox (and scaphoid fractures as snuffbox fractures), as it forms the floor of the anatomic snuffbox. A triangular deepening is seen at the dorsolateral part of the wrist, bounded by the extensor pollicis longus tendon medially and abductor pollicis longus/extensor pollicis brevis tendons laterally. This depression at the thumb base is called the radial fossa or the 'anatomic snuffbox', as it is the place where the tobacco powder is placed for snuffing (Fig. 8a). ${ }^{1}$ Snuffing was a popular social and recreational activity in the 15th to 17 th centuries, before it was replaced by smoking. It was mostly practiced by the rich, who used to carry the snuff in small, decorative snuffboxes (Fig. 8b). ${ }^{1}$ The prefix 'anatomic' was added to 
(a)

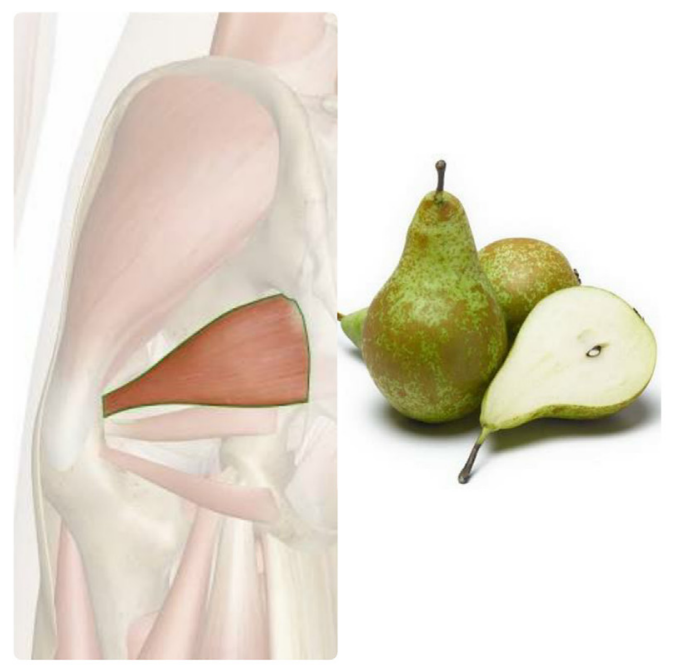

(c)

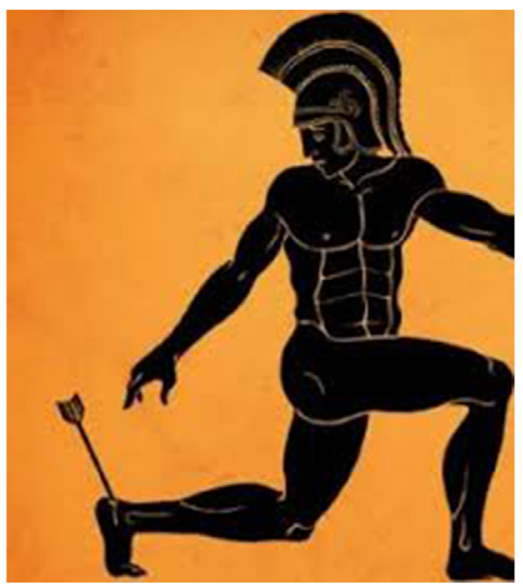

(b)

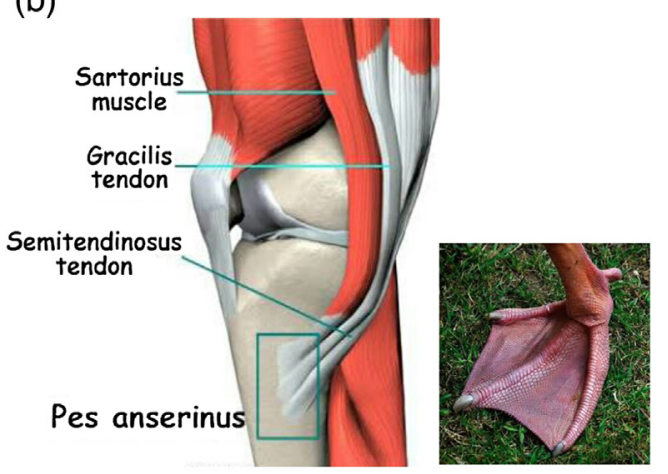

(d)

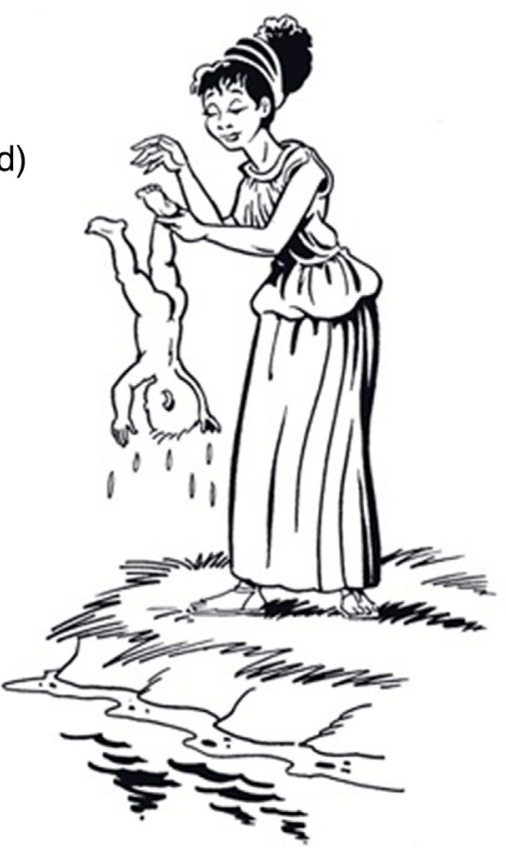

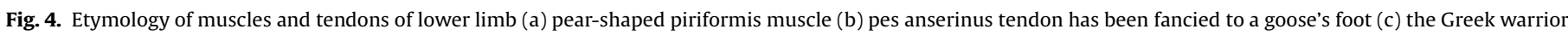
Achilles being shot at his heel chord (d) Mother of Achilles dipping him in the river Styx.

the snuffbox of the wrist only to differentiate it from the actual snuffbox!

The muscles of the upper limb, as in the lower limb, are named on the basis of their shapes e.g. deltoid (triangular), triceps (threeheaded), teres (round) major/minor; location e.g. supra-/infraspinatus (above/below scapular spine), coracobrachialis (from coracoid to arm), anconeus (elbow), interossei (in between bones); or function e.g. pronator/supinator, flexor/extensor carpi radialis/ ulnaris. 'Lumbricals' (worm-like) have been named based on their tortuous course fancied to that of worms (Fig. 9a). ${ }^{1}$ These are unique muscles in the body, having tendinous rather than bony attachments. They originate from tendons of flexor digitorum profundus and insert at the extensor expansion near the metacarpophalangeal joint.

The biceps muscle attaches distally on the radial tuberosity through biceps tendon and the medial border of ulna through bicipital aponeurosis. The bicipital aponeurosis is also called 'lacertus fibrosus' because of a fancied comparison to the tail of a lizard (Fig. 9b). ${ }^{1}$ It protects the deep structures in the cubital fossa, as during venesuction. It needs to be released in various surgical procedures, like during fasciotomies for compartment syndrome and median nerve entrapment syndrome at elbow (lacertus syndrome ${ }^{8}$ ).

\subsection{The back}

The spinal column consists of 26 vertebrae in adults- 7 cervical, 12 thoracic, 5 lumbar, sacrum and coccyx. The first and last two of these have an interesting etymology. The first cervical vertebra has been named as 'atlas', based on the Greek mythological figure Atlas. Like Atlas was condemned to hold up the sky for eternity after the Battle of the Titans (Fig. 10a), the first cervical vertebra holds up the globe of the head. ${ }^{1}$ The second cervical vertebra has been named 'axis', as it forms the pivot around which the head and the first cervical vertebra together rotate around the rest of the trunk. Historically, it has also been referred to as epistropheus (to pivot upon) for the same reason. ${ }^{3}$ It has a tooth-like process called the 'odontoid' or dens (tooth).

The etymology of sacrum is embedded with much controversy, with so many different explanations given by the historians that it has been the subject of a paper in the past. ${ }^{9}$ The word sacrum has been derived from the Greek word heiron meaning holy or sacred. ${ }^{9}$ Though some argue that the name also means 'strong', referring to the large size of the bone ('vertebra magna'), or is derived from 'sacrifice' as it was the part of animals sacrificed in religious rituals; but the most accepted meaning of the name is 'sacred or holy', and the bone was called 'the holy bone' in the 
(a)

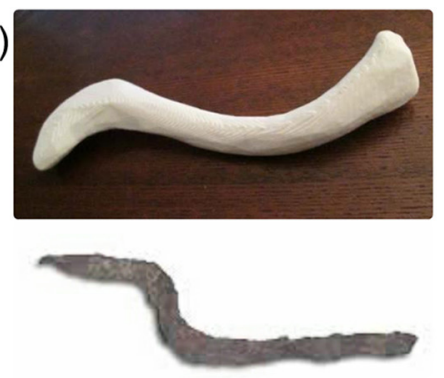

(b)

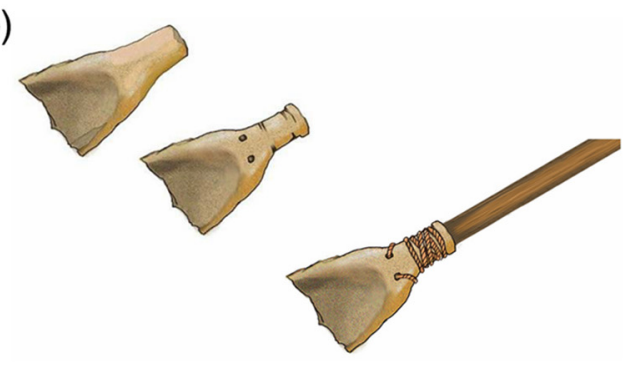

(c)

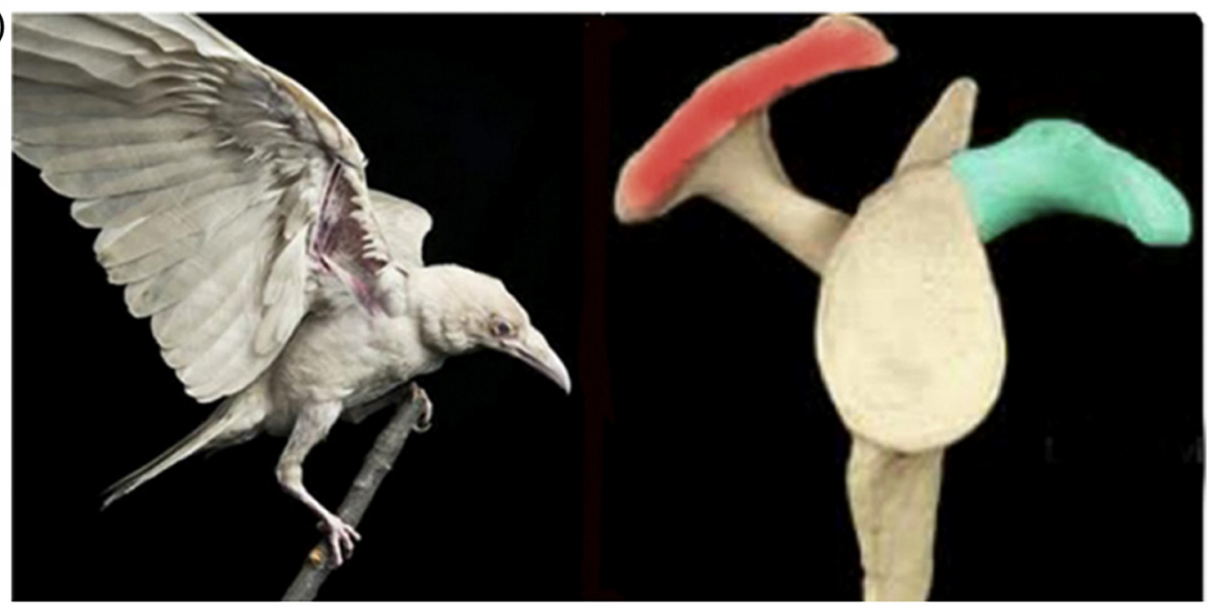

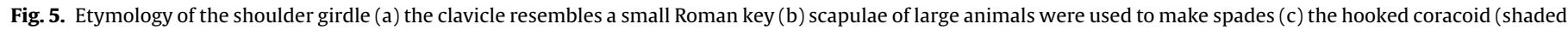
blue in the figure) resembles beak of a raven; acromion (shaded red in the figure) is the highest point of shoulder.

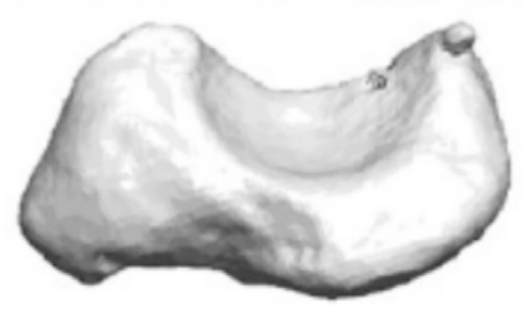

(a) (b)
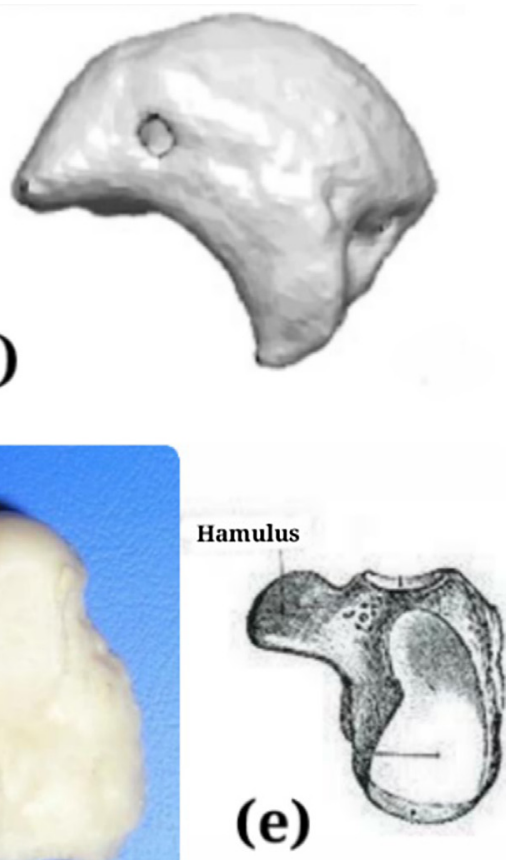

(c) For hamate

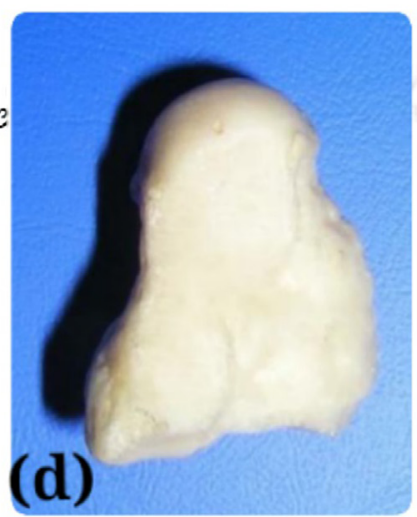

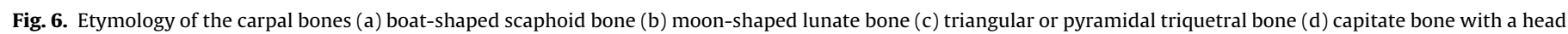
and neck (e) hamate bone with a hook (hamulus). 

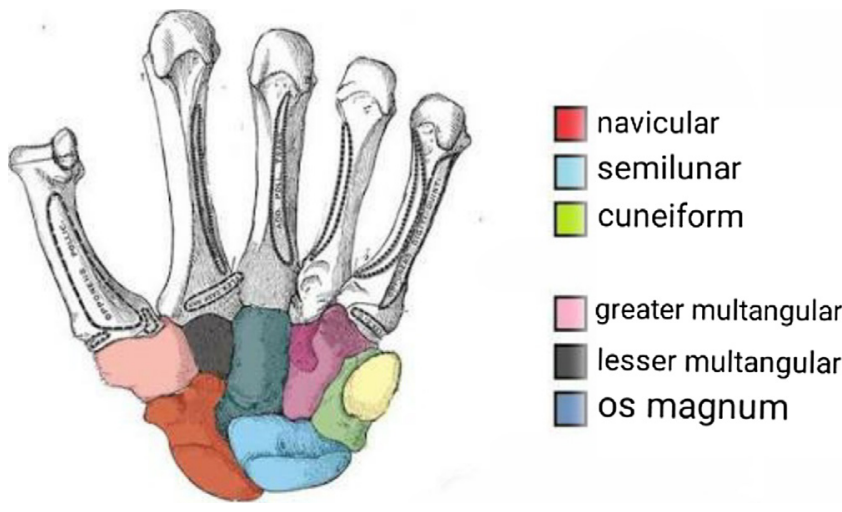

Fig. 7. Historical names of carpal bones.

past. $^{1,9}$ The holiness has also been attributed to the bone in different ways, like some believe that it covers or protects the reproductive organs which are holy organs, while others attribute it to the belief that the soul of man resides there. A more plausible explanation is that the holiness of the sacral bone was an attribute borrowed from the ancient Egyptians, who considered the bone sacred to Osiris, the god of resurrection. ${ }^{9}$ The Greek also believed the bone to be necessary as a nidus for resurrection on the Judgement Day.

The tailbone has been named as coccyx (cuckoo) as the bone resembles a cuckoo's bill or beak (Fig. 10b). ${ }^{4}$ The coccyx has also been derogatorily called the 'whistle bone' due to its proximity to the anus through which the flatus is passed with a whistling sound. It is amusing that two adjacent bones, like sacrum and coccyx, have

(a)

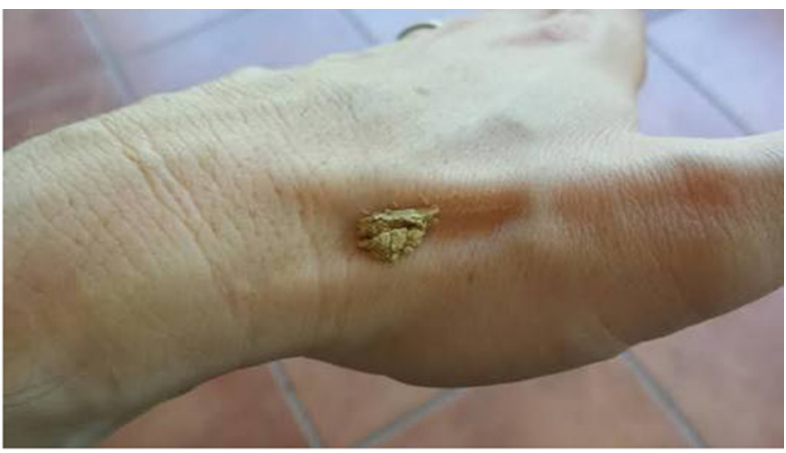

(b)

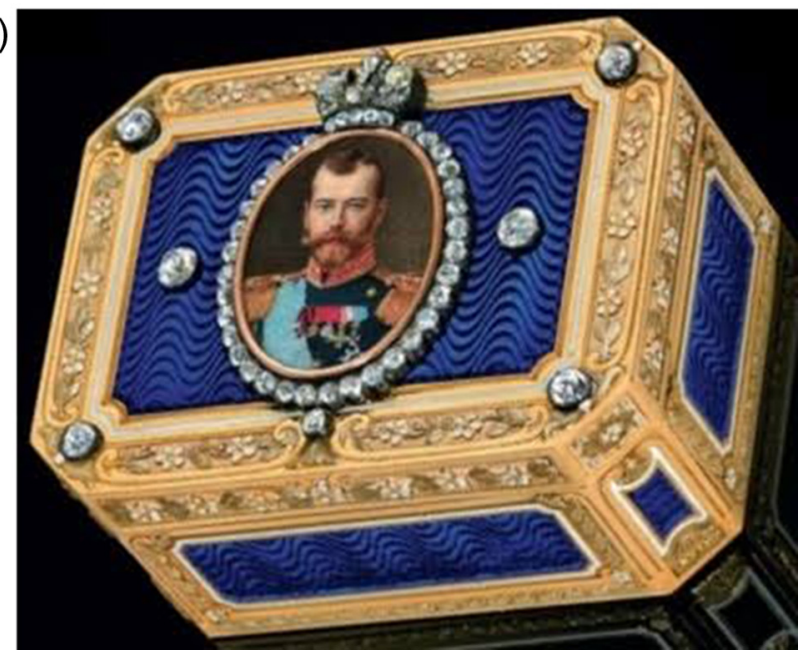

Fig. 8. Etymology of radial fossa or 'anatomical snuffbox' (a) the radial fossa is used to place the tobacco snuff while snuffing (b) a decorative snuffbox.

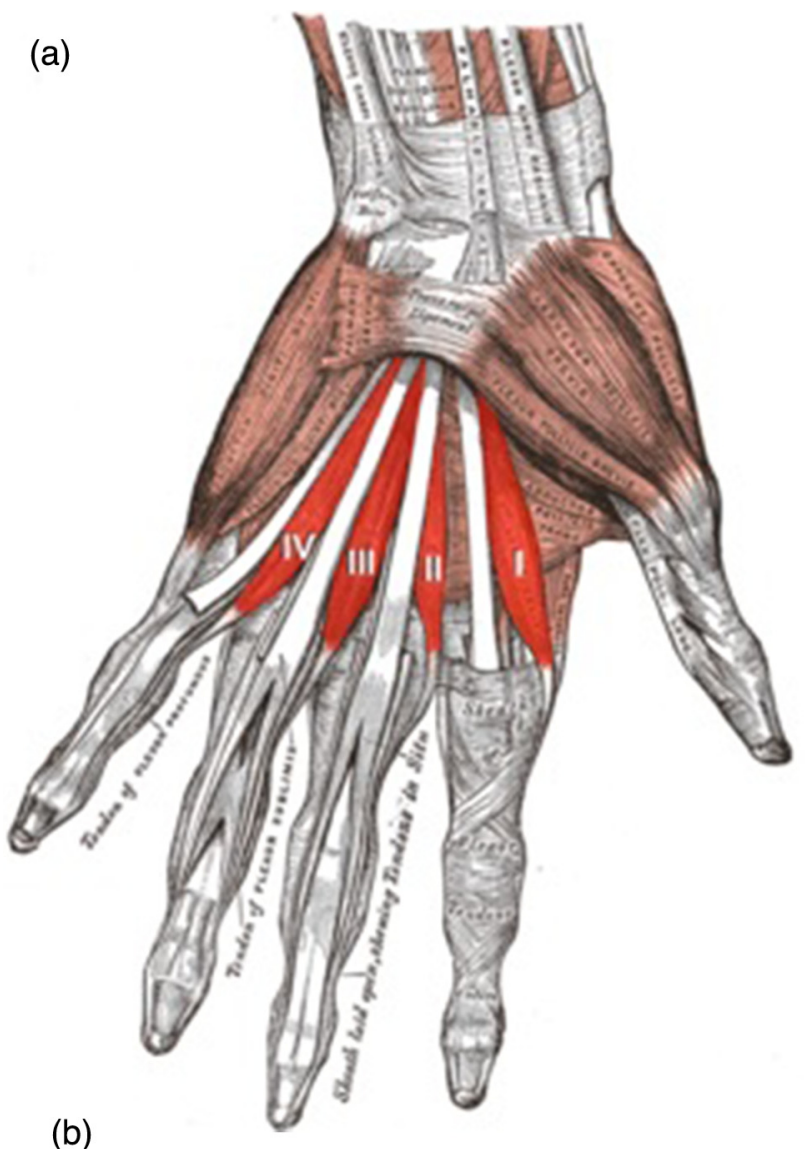

(b)

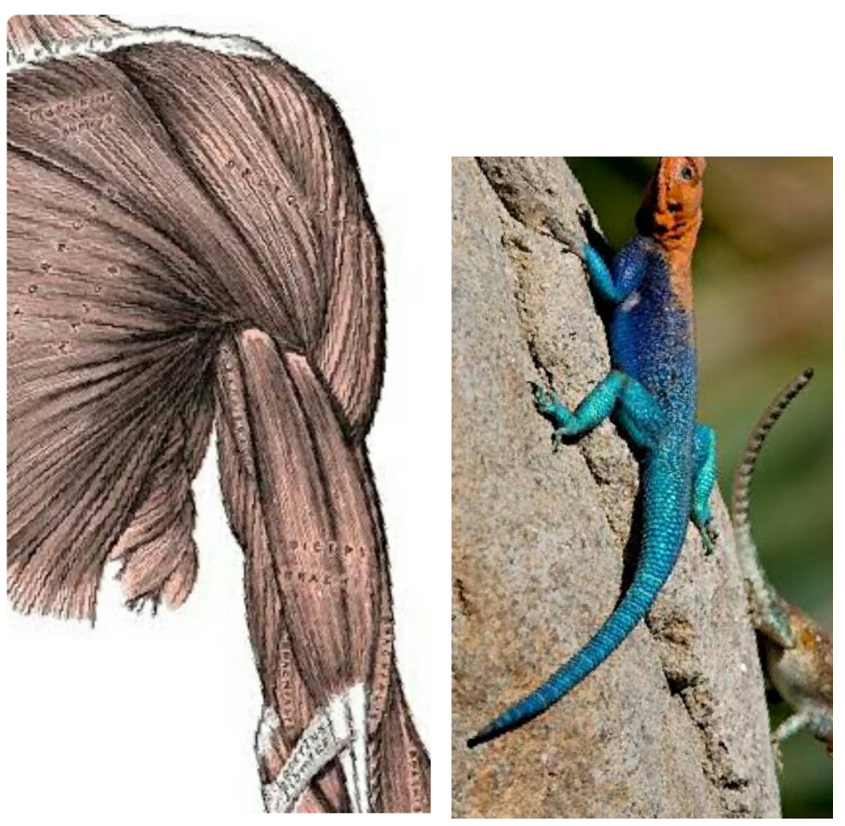

Fig. 9. Etymology of muscles and tendons of upper limb (a) the tortuous course of lumbricals muscles resembles that of worms (b) the bicipital aponeurosis or 'lacertus fibrosus' has been fancied to the tail of a lizard.

been perceived so differently- one called the holy bone and the other whistle bone!

The muscles of the back are divided into three layers or groupssuperficial, intermediate and deep (intrinsic). These are mostly named on the basis of their appearance e.g. trapezius, rhomboid 
(a)

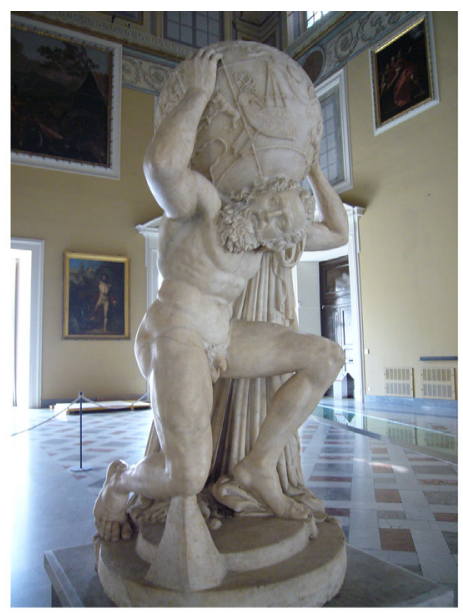

(c)

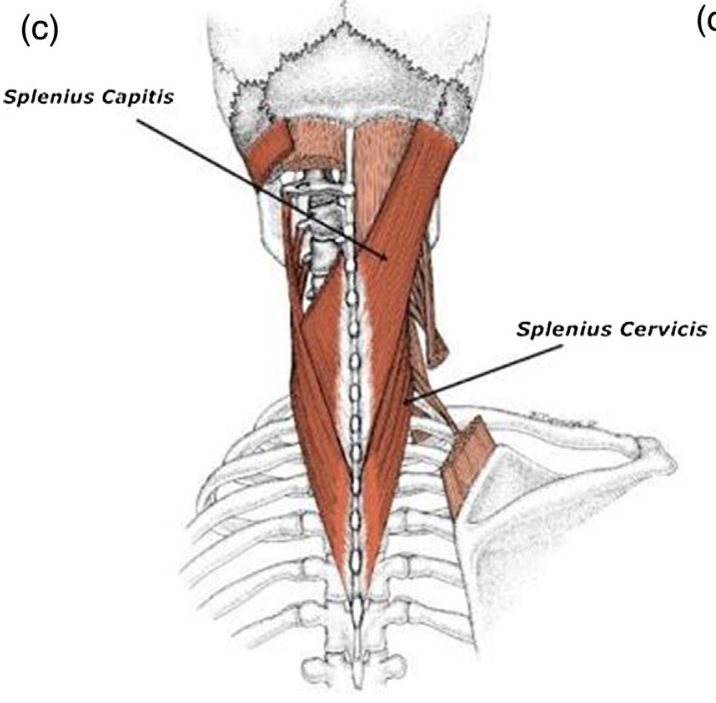

(b)
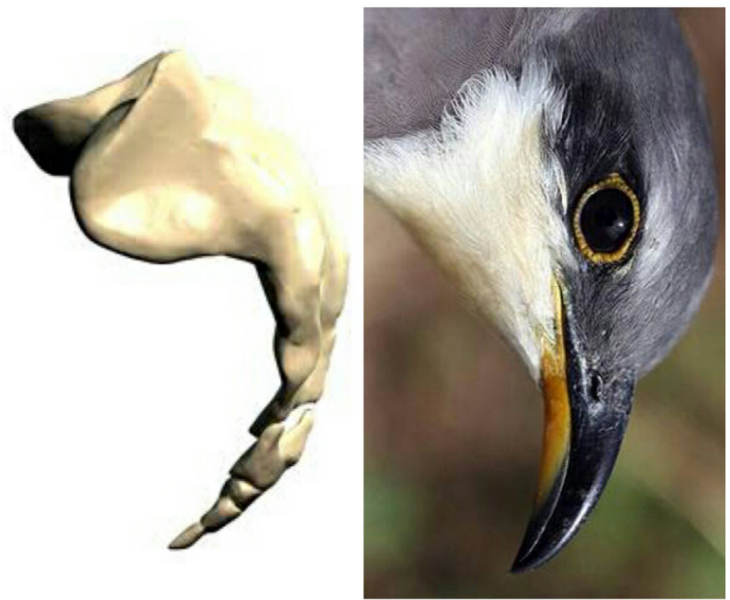

(d)
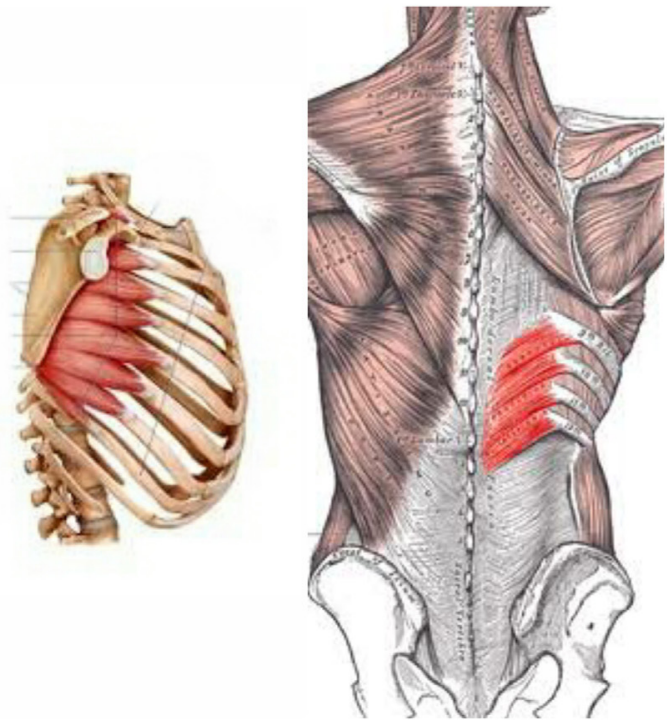

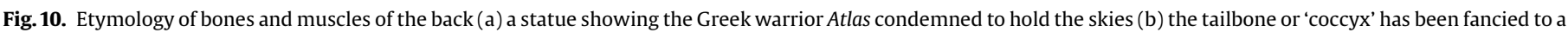
cuckoo's bill (c) the splenius capitis and cervicis muscles look like a patch or a bandage (d) saw-like serratus anterior and posterior muscles.

major/minor, splenius (patch or bandage, Fig. 10c) capitis/cervicis, serratus (saw-like, Fig. 10d) anterior/posterior; location e.g. iliocostalis, interspinalis; or function e.g. levator scapulae, rotatores. ${ }^{3}$ The longissimus (longest) and latissimus (broadest) dorsi muscles are particularly large muscles named on their appearance.

\section{Discussion}

Early medical traditions include those of Babylon, China, Egypt, Greece and India. The Greeks introduced the concepts of diagnosis, prognosis and medical ethics, though similar concepts were mentioned in ancient Indian medical texts, like Sushruta Samhita and Charaka Samhita. ${ }^{10}$ The practice of cadaveric dissection to learn anatomy was propagated by the famous Greek physician Galen, though it finds mention even in Sushruta Samhita. ${ }^{10}$ Galen's work was monumental and retained authority for the next thousand years, and the field of medicine remained relatively static (like most other fields) during the Middle Ages. In the 16th century, Andreas Vesalius did a rigorous, scientific study of anatomy and wrote his treatise De humani corporis fabrica, which built upon Galen's work. ${ }^{10}$ This laid the foundation for future anatomic studies and descriptions, which are thus heavily based on the Greek and Latin languages, making it difficult for the modern day physician or medical student to understand. Currently, Terminologia Anatomica is the official international terminology of human anatomical structures, drafted by the Federative Committee of Anatomic Terminology in 1997. ${ }^{11}$ Though it is debatable whether detailed knowledge of etymology facilitates understanding and memorising medical terms, or rather adds unnecessary details to an already vast subject; but it can be safely concluded that it helps in understanding ancient human cultures and practices, providing a useful insight into evolution of medicine and mankind.

In this paper, we have briefly reviewed the musculoskeletal etymology of the upper limb, lower limb and the back (Table 1), highlighting interesting usage of animal and human bones in ancient civilisations. To the best of our knowledge, such a review of musculoskeletal etymology has hitherto not been published in the literature. Since the Stone Age, early man picked up human and animal bones from their dead remains, using them as tools and instruments. The advent of metal technology in the Bronze and Iron ages later replaced these natural tools with metal ones. Such use of bones is reflected in their medical nomenclature e.g. scapula, tibia, talus etc. Mythology held a prominent place and belief in all ancient cultures, and certain figures of Greek and Roman mythology (e.g. Atlas, Achilles) have also inspired medical nomenclature. In several other instances, 
Table 1

Etymology of the bones and muscles of the limbs.

\begin{tabular}{|c|c|c|c|}
\hline S. No. & Name of the structure ( $\mathrm{B}=$ bone, $\mathrm{M}=$ muscle, $\mathrm{T}=$ tendon $)$ & Meaning of the term $(\mathrm{G}=$ Greek, $\mathrm{L}=$ Latin $)$ & Illustration \\
\hline 1. & Pelvis (B) & Large bowl/basin (L) & - \\
\hline 2. & Acetabulum (B) & Vinegar cup (L) & Fig $1 b$ \\
\hline 3. & Pectineus (M) & Comb $(\mathrm{L})$ & Fig $1 \mathrm{a}$ \\
\hline 4. & Piriformis (M) & Pear-shaped (L) & Fig $4 a$ \\
\hline 5. & Pes anserinus $(\mathrm{T})$ & Goose's foot (L) & Fig $4 \mathrm{~b}$ \\
\hline 6. & Patella (B) & Dish/pan $(G)$ & - \\
\hline 7. & Tibia (B) & Flute (L) & Fig $2 \mathrm{a}$ \\
\hline 8. & Fibula (B) & Broach $(\mathrm{L})$ & Fig 2b \\
\hline 9. & Tendoachilles ( $\mathrm{T}$ ) & Greek warrior Achilles (G) & Fig $4 \mathrm{c}, \mathrm{d}$ \\
\hline 10. & Talus (B) & Die $(\mathrm{L})$ & Fig $3 a$ \\
\hline 11. & Calcaneum (B) & Chalk stone (L) & Fig $3 b$ \\
\hline 12. & Navicular (B) & Little ship (L) & Fig $3 c$ \\
\hline 13. & Phalanx (B) & A military formation $(\mathrm{G})$ & Fig 3d \\
\hline 14. & Clavicle (B) & Small key/bolt, tendril (L) & Fig $5 a$ \\
\hline 15. & Scapula (B) & Spades/shovels (G) & Fig $5 b$ \\
\hline 16. & Coracoid (B) & Crow/raven $(G)$ & Fig $5 c$ \\
\hline 17. & Lacertus fibrosus & Lizard (L) & Fig $9 b$ \\
\hline 18. & Scaphoid (B) & Boat-like (G) & Fig 6a \\
\hline 19. & Lunate (B) & Moon-shaped (L) & Fig $6 b$ \\
\hline 20. & Triquetrum (B) & Triangular/pyramidal (L) & Fig $6 c$ \\
\hline 21. & Capitate (B) & With a head (L) & Fig $6 \mathrm{~d}$ \\
\hline 22. & Hamate (B) & With a hook (L) & Fig $6 e$ \\
\hline 23. & Lumbricals (M) & Worm-like (L) & Fig 9a \\
\hline 24. & Atlas (B) & Mythological figure (G) & Fig 10a \\
\hline 25. & Sacrum (B) & Sacred, strong (G) & - \\
\hline 26. & Coccyx (B) & Cuckoo $(G)$ & Fig 10b \\
\hline 27. & Splenius capitis/cervicis (M) & Patch/bandage (G) & Fig $10 c$ \\
\hline 28. & Serratus anterior/posterior (M) & Saw-like (L) & Fig 10d \\
\hline
\end{tabular}

the names of bones and muscles were based on their appearance, drawing an analogy to day-to-day objects like household items (e.g. patella, fibula), fruits and vegetables (e.g. pisiform, piriformis), birds and animals (e.g. coccyx, lumbricals) and wars and weapons (e.g. phalanx). Wars have greatly impacted the evolution of mankind and medicine, and a large number of musculoskeletal colloquialisms have been based on arms and weapons. ${ }^{12}$ Acquaintance with etymology and colloquialisms can be useful in understanding musculoskeletal anatomy and pathology.

\section{Conflict of interest}

None.

\section{Source of funding}

None.

\section{Acknowledgement}

None.

\section{References}

1. Diab M, ed. Lexicon of Orthopaedic Etymology. Amsterdam: Harwood Academic Publishers; 1999 [ISBN 90-5702-597-3].

2. Dirckx JH, ed. The Language of Medicine-Its Evolution, Structure and Dynamics 2nd ed. New York: Praeger Publishers Inc.; 1999 [ISBN-13: 978-0030639616]

3. Taylor RB. The Amazing Language of Medicine- Understanding Medical Terms and Their Backstories. Switzerland: Springer Nature; 2017 [ISBN 978-3-319-503271].

4. Cunningham C, Scheuer L, Black S, eds. Developmental Juvenile Osteology. 2nd ed. London: Elsevier; 2016 [ISBN: 978-0-12-382106-5].

5. Parker G, ed. The Cambridge Illustrated History of Warfare: the Triumph of the West. Cambridge: Cambridge University Press; 2008 [ISBN: 978-0-521-73806-4].

6. Stevenson A, ed. Oxford Dictionary of English. 3rd ed. Oxford: Oxford University Press; 2010 [ISBN: 978-0-19-957112-3].

7. Helfenstein Jr MJr, Kuromoto J. Anserine syndrome. Rev Bras Reumatol. 2010;50 (May-June (3)):313-327.

8. Lalonde D. Lacertus syndrome: a commonly missed and misdiagnosed median nerve entrapment syndrome. BMC Proc. 2015;9(Suppl. 3):A74.

9. Sugar O. How the sacrum got its name. JAMA.1987;257(15)2061-2063 [Apr 17]

10. Singh J, Desai MS, Pandav CS, Desai SP. Contributions of ancient Indian physicians- Implications for modern times. J Postgrad Med. 2012;58(JanuaryMarch (1)):73-78.

11. Walker-Esbaugh C, McCarthy LH, Sparks RA. Dunmore and Fleischer's Medical Terminology- Exercises in Etymology. 3rd ed. Philadelphia: F. A. Davis Company; 2004.

12. Agrawal A. Musculoskeletal colloquialisms based on weapons. J Clin Orthop Trauma. 2017;8(1):1-1010.1016/j.jcot.2016.07.006. 